\title{
Factors Affecting Management Control System Some Cultural Aspect
}

\author{
Oleh : Achmad Soblrin
}

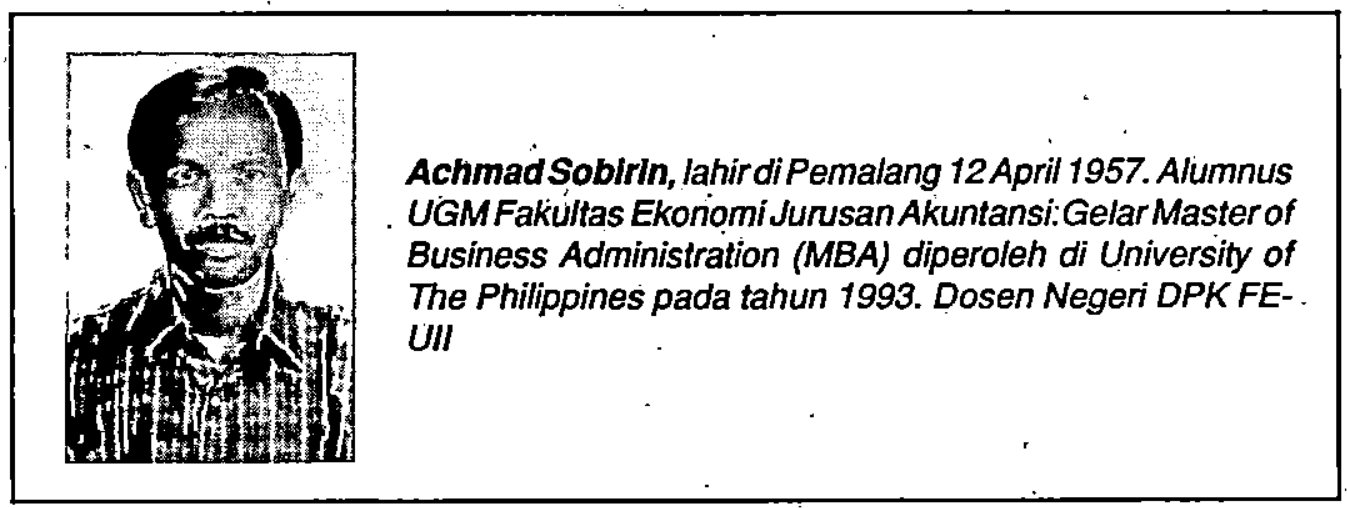

\section{Introduction}

Since Japanese economy continues to grow dramatically, no foreign country has received more etention from students of management than Japan. Dozens of books and hundreds of articles have been written on the subject. Americans and other Westem pople have tried to evaluate the Japanese success. They analyze particularty the way the Japanese manage theor pople. As they have found. Japanese culture has been ' considered as one of the key success factors. Pascale and Athos (1981) for instance, said that Japanese culture gives them advantages in the skills, styles, staff and superordinate goals. In addition, McCo Rmark (1989) marvels at the personal qualities of Japanese businessmen and theirtalent formotivating workers.

Yet; how does one gain an understanding of other countries like Indonesia for there have been few studies which focus directly or indirectly upon developing country in organizational behavior? Unfortunately, most of concepts that currently make up the American subjects, within domestic contexts. Moreover approximately eighty percent of studies on management and organizational behavior over a ten-year period were done in the United State and had been conducted by Americans (Robbins, 1991). This would mean that not all the concepts may be universally applicable to manage pople around the world. In the case of management control system, for example, it is basically the same concepts wherever it will be used. However, one must consider culture factor if the concept is to be used in different countries (Anthony, Dearden and Belford, 1984).

The pupose of this paper is to explore some cultural factors which might affect the effectiveness of management control system (MCS), particulatly when this system is to be applied in a country which differs from the country in which the MCS 
was developed, If so, how manager should design this system.

In order tolimitdiscussion, Indonesia setting will be brought into focus. Indonesia is considered developing country which is its economics growth fosteredby industrialization. Since 1967, when Soeharto administration introduced orde baru or new order, as a goverment policy, Indonesia has become an opened economic country. Foreign investment, therefore, become an altemative source of funds. After more than 20, years, since this policy was fpomulgated, more and more multirlational corporations (MNCs) operate in Indonesia and gradually the country is shifting from an agrarian to an industrial economy. This MSCs, however, have to take the from of joint venture businesses and should include an Indonesia equity partner from the onset of operation. MNCs also have to employ Indonesia nationals as much as possible and train Indonesian in technology and management skill, although at the same time, employment of expatriate workers is widely permitted. The implication is that the operation of MNCs may be managed both by foreign managers and Indonésian managers. If this is the case, conflict may occur becuse of factors, considering that Indonesian culturally differs from western country.

Regarding this fact if, MNCs is willing to use MCS as management control device, then they must take culture consideration into account.

\section{The Concept of MCS}

Every organization have goals either explicitor implicit, which represent a board, a fairly timeless statment of that the or- ganization desires to achieve attain the goals, the organization needs strategies that includes policies to guide ways of acting and broad programs of activies. And to assure that people in the organization do perform their duties, management needs some ways which is called control.

Control as a process follows' a cybernetic paradigm to ensure attainment of goals. It has detector, selector, effector and communication network. Control device used in organization, however, are much more complex than those used in machinary, i.é auto mobile, refrigerator or air condition ing; primary becuse control of organization is a much complicated process. It is related to the human beings whose reaction is uncertain when they know, for instance, that their performance is not according to the plan. In organization, people, therefore are regarded as the most important variable to be directed, guided, and motivated to pursue goals.

To do so, then, responsible managers are needed. Their role in control is called management control. Thus, management control is a process by which management assures that the organization carries out its strategies. It consists of all methods, procedures, and deviced, including MCS.

Management control system, may then, be defined as an organized systematic process and structure that management uses is management control ( $A D$ and $B, 1984$ ). This definition implies that MCS is a formal control system to ensure that the organization accomplishes its strategies and persues its goals. It encompasses both management control structure and management control process. Management 
control structure refers to units in organization and the nature of information that flows among these units, whilemanagement control process refers to what managers do with this information. There appears to be six characteristics that, when mixed and matched, tap the essence of a formal MCS. 1. MCS focus on programs and responsibility centers.

2. Information processed in MCS consists of planed data and actual data.

3. MCS is total organization system embraces all aspects of organization operations.

4. MCS is usually built around a financial structure.

5. The planning aspects of MCS tend to follow a definite pattem and timetable.

6. MCS is a coordinated and integrated system.

\section{Management Control Structure}

Management control structure consists of two basic elements, organization units and information flow among these units. Unit in organization by a responsible manager iscalled responsibility center. Each centerhas inputs-the resources and services the unit consumes and outputs-the goods or services created by a unit. Both are measured in monetary unit. The degree to which these inputs and outputs are measured and for which manager is responsible is used to classify responsibility centers. Based on this criteria, then there are four types of responsibility center--expence center, revenue center; profit center and investment center.

Expense center refers to responsibility center in which inputs are measured in monetary terms while outputs are not, and manager is primary responsible for expense control. Department of production is an example. Production manager is responsible to minimize or, sometimes, for the efficiency of production costs. Expense center, futher, is distinguished between engineered and discretionary expense center in engineered expense center, costs are. scheduled as discribed before while in discretionary center, costs can be varied at the discretion of manager.

Revenue center refers to responsibility center in which both inputs (expenses) and outputs (revenues) are measured in monetary unit. Revenue and expense are matched to calculate profit. In this center, manager is responsible both for expense and revenue control.

Investment center refers to responsibility center in which inputs and outputs are measured in term of money as well as investmentused in that responsibility center. In thus center the manager is responsible not only for maximizing profit but also for the effeciency of investment being used.

The second element of management control structure is information. In order to control activities, each manager in responsibility center collects, analyzes, evaluates and uses information. This information flows among the responsibility centers according to the structure and the nature of information and the management needs (Awad, 1988).

The structure of information may be described in tenn of three catagories and three level of decision making: stralegy, managerial and operational. Strategical information is future oriented, involving uncertainty. It deals with long-range planning, which is the task of upper manage- 
ment. Managerial information is useful to the middle mangement which focuses on policy implementation. It is used short term planning.

The nature of the information and the managerial level are also related to the three catagories of decision making structure, semistructure and unstructure. Lower management dealing with operational information generally makes structure decisions. In contrast, upper management dealing with strategic information makes judgemental decision and thus unstructure. In terms of detailed information, lower level expects detailed operational information for dealing with day-to-day structure decision, while upper level requires summarized from varioussources. The management level and information catagories are shown in figure $1 . \therefore$.

\section{Management Control Process}

Management control process starts with the preparation of the plans. These plans are made within the context of strategies decided on in the strategic planning - process. They are expressed as programs, budgets; operating and measurement, and reporting and analysis.

Programming is the first step in the management control process. It is defined as the process of deciding on the nature and the size of several programs to be undertaken in implementing an organization's strategy. Programming is usually' considered as a long-run planning. This is because programming focuses on activities that extend over a period of several years. The result of programming are programs which indicate which, when, and what amounts of resources will be used on each program, product lines

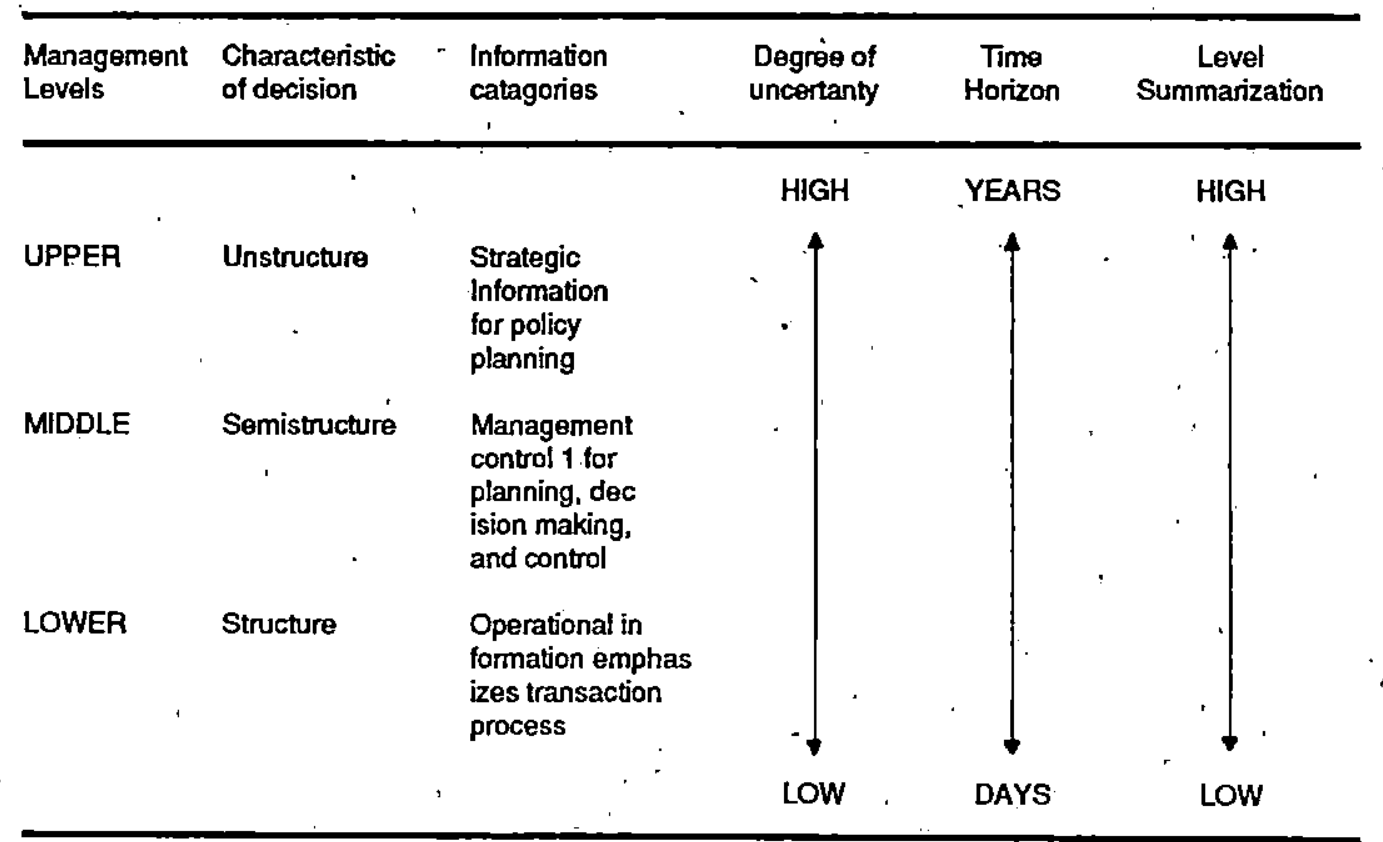

Management level and information catagories 
or other programs. In other word, it can be said that programming is structured based on product, product line or programs.

The second step in management control process is budgeting. Like in programming, budgeting process also involves planning. However, the difference is that budgeting process focuses on a single year, whereas programming focuses on activities that extend over a period of several years. Budgeting also differ from programming in term of its structure. While programming is structured by product lines or on major program, budgeting is structured by responsibility centers. The purpose of the budgeting process is to work out detailed plans for implementing these program decisions.

Budget is a plan expressed in quantitative, usually in monetary unit. It covers. a specified period of time, usually one year. Budget serves several purposes. It used as device for making and coordinating plans, for communicating these plans to those responsible for carrying them out, and for motivating managers at all levels; as a benchmark for controlling ongoing activities; as a standard with which actual perfornance subsequantly can be compared; and a means of educating managers.

The first two step in the control process mentioned above indicate the differcnt structure of programing and budgeting. These two steps relate to the third step, operating and measurcment. Actual data. both.expenses and revenues, are recorded during the operations. These data are classified both by programs and by responsibility centers. Data classified by program are to be used as a basis for future programming and those classified by responsibility centers are to measure the performance of responsibility center managers.

Reporting and analysis are also as part of control process. Actual performance are compared with planned performance and any variances should be analyzed and explained. Based on this explanation, managers decide what actions should be taken.

\section{BEHAVIOR ASPECTS OF MCS}

Aside from formal control system as described above, MCS also infolves behavior aspects of people in organization. MCS is useless without considering this aspect. This is because of the crucial role of people in the organization. From the lowest up to the highest responsibility centers consist of people. Management control process are done by people as well, they do programs and execute budgets and they are evaluated according to their performance. In other word, management in the organization cannot literally control, for example, the cost of various activities. What they can do is control the action of people who are responsible for incurring these costs.

People in the organization are actually the central issue of MCS. People with diverse social backgrounds, cultural orientations and educational trainings join an organization because they believe that by doing so the can achieve their personal goals which may be difficult if these are to be done alone. Their contribution to the organization is based on the perception that this eill help achieve their personal goals. Their behavior in organization is therefore influenced by their motivation which further will also be affected by their needs (Anthony, Welsch and Recce, 1985): A model of motivation for example, can be 
seen in figure 2 (David and Newstorm, timent that can motivate the people in or1989). ganization to work toward conmon goal. It

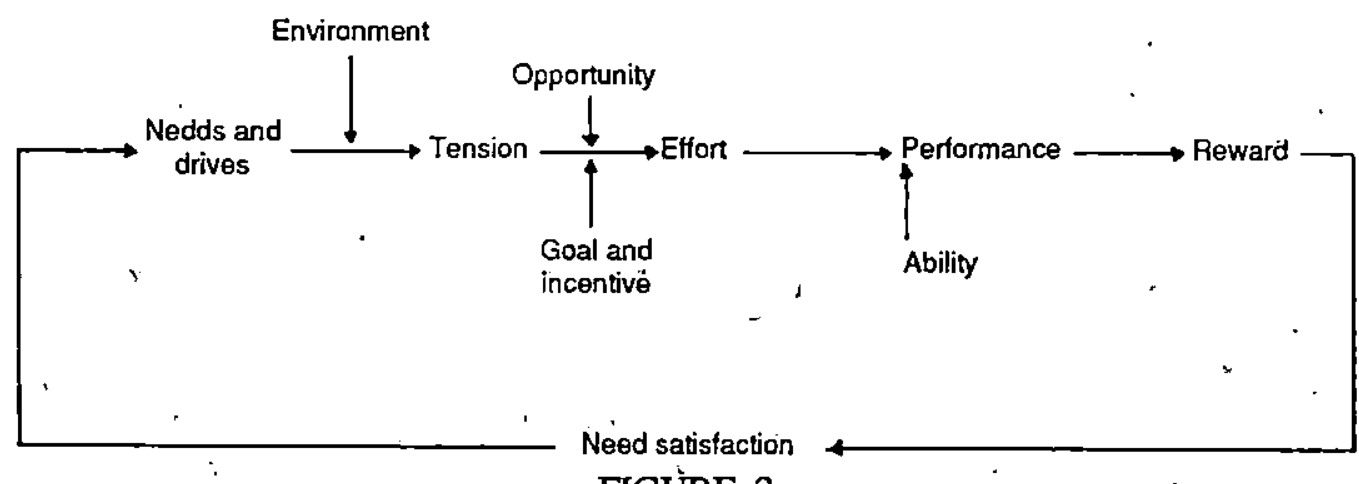

FIGƯRE 2

This model explains the role of motivation in performance. Needs and drive create tension that are modified by one's environment, including culture, value and norm, while performance is a product of effort and ability, within a context of opportunity to perform. When the employee is productive and the organization takes note of it, rewards are distributed and this results in employee's satisfaction.

On the other hand, organization it self has goals. Organizational goals are actually the goals of top management. Top management determines the goals, communicates these goals to the lower level management and motivates them to attain the goals. Unfortunately, personal goals. may not be supportive of organizational goals.

The difference between organizational and personal goals suggests that $M C S$ should be designed so as to encourage goal congruence - the goal of people in the organization consistent with the goal of organization as a whole. The managers are responsible for achieving this end. It is their job to level these difference and mold them into a commonly shared organizalion sen- is their responsibility to motivate people to participate creatively and productively so that the organization can achieve its goals. As Lee Iacocca said "Management is nothing more than motivating people".

Compared to formal control system which deals with what is to be done on the basis of empirical evidence, behavior aspect of MCS deals with how best things can be done productively with the least conflict. These two approaches must be hamonized into organizational orientation.

\section{THE IMPACT OF CULTURE ON PER- FORMANCE .}

Asdescribed in figure 2, performance of people or managers in organization are affected by their environment. This is because organization is part of a larger society. It is continually interacting with its environment. This is a two way interaction which organization affects the outside world and vice versa. Since organization is part of society, then it is not an isolated entity. People in organization interact both withing and outside the organization. The behavior of any one member can have an impact, directly or indirectly, on the behavior of 
others. Although these impacts may be strong or weak, all parts of the society affect all other parts. Each responsibility centermanager is therefore responsible not only for the work done within responsibility center but also for responsibility center's relationship with outside world.

Culture has been considered as part of environment which has great impact on the way people behave. Culture, by definition is society's symbol system and the information they convey (Lenski and Lenski, 1987). This definition implies that culture consists of symbol systen and information. A symbol refers to any object, idea, sound or act to which the observer's attribute meanings specify what is intended, signified, indicated, and understood when using the object, sound, and act. It is from the symbolic perspective of culture that we can grasp clearly the nuances or subtieties of human behavior in community or in organization. It is from these intangibles that we can find clues for understanding why people behave in particular way.

Cultural information is knowledge acquired through experience and conveyed through symbols. It passe down from generation to generation through the leaming process to prescribe the behavior of the society. Once internálized, itbecomes forms of rationality, provide the individual and the group with common point of reference for behavior and enhance the sharing values, beliefs, norms and practices.

Culture then plays atremendous role in the patteming of human behavior and organizations. Themes and pattems of everyday life of people and their behavior are affected by theirculture. Although value, nom and belief are non-observable so that culture is often elusive, behavior is however an observable one. Meaning to say that by understanding the national culture of a certain country, a manager knows how the people behave and perform their duties, and in turn, he can easily encourage and motivate them to attain the organizational goals which is actually the objective of top manager setting MCS.

\section{ABOUT INDÓNESIAN CULTUURE}

As an Indonesian, it is difficult for me when asked what Indonesian culture is, what Indonesia people look like, and how they behave. I can understand how things are done and work comfortably within unwritten norms but I can not delineate clearly. This is because culture is to the people like water is to fish (Robbins, 1991), it' is already there all the time. Fortunately behavior is observable, thus by comparing with another cultures, for instance, with Philippines, Japanese or American; Indonesian culture can be explained roughly.

Another problem of accurately describing Indonesian culture is that Indonesia consists of many tribes who have their own culture. It means that national culture of Indonesia encompasses many subcultures which affect one another.

There are more than 300 tribes in Indonesia, eight of which are very prominent, including Acehese, Batak, Balinese, Bugise, Javanese, Manado, Minangkabau, and Sundanese. These subcultures contribute to the national culture of Indonesia. Javanese is however the most prominent. It dominates almost all aspects of life in Indonesia. This is understandable because historically Indonesia comes from Madjapahit kingdom whose territory covered all Indonesia and other Southeast Asian country and its center was Java. Thus when 
we are talking about Indonesian culture, invevitably we are referring to Javanese culture.

Prof. Pưmamasidhi Hadjisarosa, a forner minister of public works of the Republic of Indonesia, on one scminar explained that basically people can be distingished by using analogue of meateater animal and cereal-eater animal. Meat eater animal tend to hunt the prey, or otherwise, they lose the prey. They are agressive, fight individually, kill or to be killed. On the other hand, cereal-eater animal tend to be passive. To do something, they tend to wait their leader do. They were in group while waiting the cereals grew up and ripe, harmony but tend to be subjugative to the nature.

This analogue can be used to depict Indonesian people compared to American and Japanese. Purnamasidhi furthermore, described that Indonesian people are like animals who eat cereals. Using McGregor's theory, It can be said that Indonesians are close to theory $\mathrm{X}$. This is because naturally Indonesia is rich, so people should not fight to have their foods. They arc less initiative because every thing grow and they just harvest. In the contrary, Americans as if they are meat eating animal, while Japanese are in between.

On the other side, F. Kluckhohn and F.L. 'strodtbeck (Robbin, 1991) explained in more detail the frameworks for analyzing variations among cultures. They emphasized that there are six basic cultural dimensions:aperson's relationship to nature, and others; the culture's orientation to time, and activity; the nature of culture's people, and the conception of space. This description can be seen in figure 3 below.

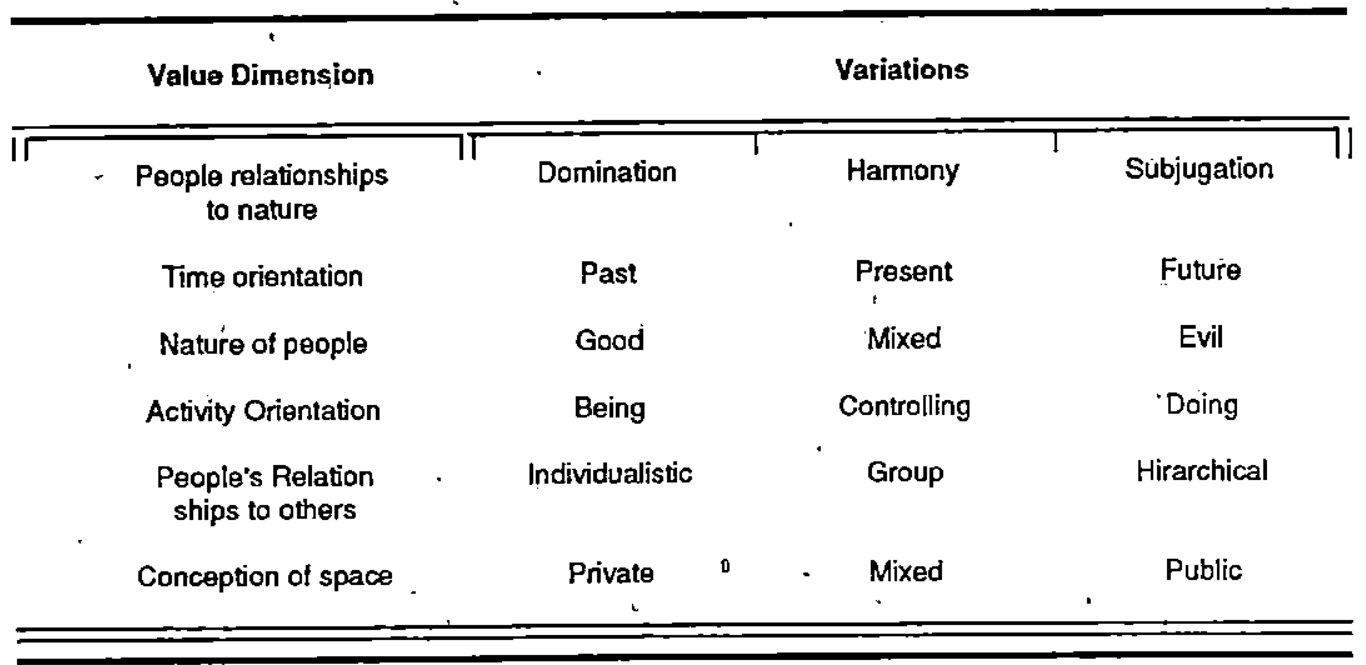

FIGURE 3 
Using this framework, Indonesian people can be described by comparing them to American. In the relationship to the nature, Indonesian people see life as essentially preordained. When things happen, they tend to see it as God's will. This perception however has changed. People seek harmony with nature according to concept of selaras dan seimbang - in harmony and in balance. In harmony society, goals are likely to be used but deviations will be expected and penalties for failing to reach the goals are likely to be minimal. American on the other hand, believe that they can control nature. They are willing to spend billions of dollars in research because they believe that nature can be controlled.

Alon-alon asal kelakon or slow but sure is a populair term in Javanese society. It indicates time dimension of Javanese culture and widely accepted by Indonesian as well. Goals are not necessarilly to be achieved in the present time. If goals can not be attained today, maybe tommorow, next week, next month or next year. Also if one cannot achieve the goal by himself, he hopes that next generation can do it. In other word, Indonesian take a longer term view to pursue goals. This is reflected in the performance appraisal method. People is not evaluated by their accomplishment but a good behavior and their effort.

On the other hand, Americans focus on the present and near future. It can be seen in the short term orientation of performance appraisals. They are evaluated every six or twelve months. They perceivc time as a scare resource. Thus it must be used efficiently.

In term of the nature of people, Indonesians see themselves as basically honest and trustworthy. Partipation of group member is very 'important, according to melu handar beni - sense of belonging concept. One will be gotten rid of every life if he/she is not according to group pattem even if he is the right one. While American is somewhere between good and evil. They see people as basically good but keep on the lookout in order not to be taken advantage of.

In activity orientation, Indoensian is being oriented. They stress experiencing life and seeking immediate gratification of desires. In culture with dominant being orientation decisions are likely to be emotional. While American, with doing orentation, are likely to emphasize pragmatism in decisions.

Culture can also be classified by where responsibility for the walfare of others lies. While American are highly individualistic, Indonesian follow another orientation. They rely on group relationships. Working well with others is likely to be of primary importance.

In term of space conception, American place a great deal of emphasis on keeping things private, while Indonesia fall between private and public. This has obvious implication for such organizational concern as communication and job design. - Direct (oral) communicative interaction appears to be difficult because it can be felt to be confrontational. If it occurs. it is top down. Parents for example, in every day life telling children what to do, and children are not supposed to answer back. Thus criticism or rebuke of subordinate should preferably be done in private and never in front of others. People are very vulnerable on face and may feel that their dignity is in stake. 
SUMMARY

Heaving understood Indonesian culture, we realize that Indonesians somewhat differ from Americans. Meaning to say that MCS, originally an American model, is not necessarily applicable to Indonesian environment. This does not mean that MCS concept is imperior. Rather, to be applicabe to Indonesian environment, this concept should be redesigned, particularly in the aspects of management control process. In order to motivate subordinates and rank and file for instance, increase wages will not necessarily motivate people to do a better performance because money is not the only criteria of reward system: One is not willing to work in such company even he will be paid by the highest wages if it is less humanist approach in that company. This is because self-actualization is more important for him than money.

Group orientation of workers, communication channel and job design, should also be taken into consideration. Since worker tend to be in group, competition in this group is very low. Tighten control then is suggested and performance evaluation should not be done individually.

Formal structure is not the only one of communication channel. Informal communacation is also suggested because workers tend to be as close as possible to their leader. When, for example manager cannot solve his problem formally, it is solvable if itdoes informally. This is because Indonesians actually avoide conflict. They tend to compromize.

\section{REFERENCES}

Anthony, Robert N., John Dearden and Norton M. Bedford. Management Control System. Fourth edition. Homewood III : Richard D. Irwin, 1984.

Anthony, Robert N.. Glenn A. Welsch and James S. Reece. Fundamental of Management Accounting. Fourth edition. Homewood III : Richàrd D. Irwin, 1985.

Awad, Elias M. Management Information Systents : Concepts; Structure, and Applications. California : The Benjamin Cummings"Publishing Co., 1988.

Davis, Keith and John W. Newstrom. Human Behavior At Work : Organizational Behavior. 8th Edition. New York : McGraw-Hill, 1989.

Jocano, F. Landa. Filipino Corporate Culture. Metro Manila: Funland Research House, 1988.

Lenski, Gerald and Jeane Lenski. Human Societies : An Introduction to Macrosociology. Fifth edition. New York : Graw-Hill, 1987.

McCormack, Mark H., What they Still Don't TheachYouAt Harvard BusinessSchool, Bantam Books, 1989.

Mulder, Neil Everyday Life Conflict and Conflict Resulition in Javanese and Tagalog Society : An Anthropological Comparison. Draft, 1991.

Pascale, Richard T., and Anthony ${ }_{1} \mathrm{G}$. Athos, The Art of Japanese Maiagement, Warner Books Edition. 1981.

Pilar, Nestor N., and Rafael Rodriguez. Readings in Human Behavior in Organizations. Quezon City : JMC Press, 1981.

Robbins, Stephen P., Organizational Theory. Englewood Cliffs, N.J. Prentice hall, 1983.

Robbins, Stephen P., Organizational Behavior : Concepts, Controversies, and Application. Fifth edition, Engelwood Cliffs, N.J : Prentice Hall, 199l. 